\title{
Y. PROTOCOLO SOBRE LOS ESTATUTOS DEL BANCO EUROPEO DE INVERSIONES
}

\section{LAS ALTAS PARTES CONTRA- TANTES}

DESEANDO establecer los Estatutos del Banco Europeo de Inversiones, previstos en el artículo 129 del Tratado,

HAN CONVENIDO las siguientes disposiciones, que se incorporarán como anexo a dicho Tratado:

Artículo 1. El Banco Europeo de Inversiones, creado por el artículo 129 del Tratado, en lo sucesivo denominado el «Banco», quedará constituido y ejercerá sus funciones y su actividad de conformidad con las disposiciones de dicho Tratado y de los presentes Estatutos.

La sede del Banco será fijada de común acuerdo por los Gobiernos de los Estados miembros.

Art. 2. La misión del Banco será la definida en el artículo 130 del Tratado.

Art. 3. Con arreglo al artículo 129 del Tratado, serán miembros de Banco:

El Reino de Bélgica:

(1) Párrafo atladido por el artículo 1 del Tratado de 10 de julio de 1975, por el que se modifican
La República Federal de Alemania;

La República Francesa;

La República Italiana;

El Gran Ducado de Luxemburgo;

El Reino de los Paises Bajos.

Art. 4. 1. El Banco tendrá un capital de mil millones de unidades de cuenta, suscrito por los Estados miembros de la forma siguiente:

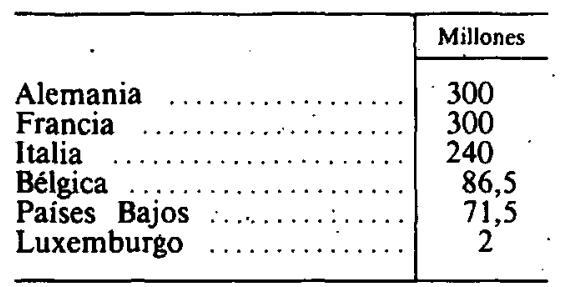

El valor de la unidad de cuenta será de 0,88867088 gramos de oro fino.

El Consejo de Gobernadores, por unanimidad y a propuesta del Consejo de Administración, podrá modificar la definición de la unidad de cuenta (1).

determinadas disposiciones del Protocolo sobre los Estatutos del Banco Europeo de Inversiones. 
Los Estados miembros sólo serán responsables hasta el importe de su cuota de capital suscrito y no desembolsado.

2. Lá admisión de un nuevo miembro llevará consigo un aumento del capital suscrito correspondiente a la aportación del nuevo miembro.

3. El Consejo de Gobernadores podrá decidir, por unanimidad, un aumento del capital suscrito.

4. La cuota de capital suscrito no podrá ser cedida ni pignorada y será inembargable.

Art. 5. 1. Los Estados miembros desembolsarán el 25 por 100 del capital suscrito en cinco pagos iguales, que deberán efectuarse, respectivamente, a más tardar, dos meses, nueve meses, dieciséis meses, veintitrés meses y treinta meses después de la entrada en vigor del Tratado.

Una cuarta parte de cada desembolso se hará efectiva en oro o en moneda libremente convertible, y las tres cuartas partes restantes, en moneda nacional.

2. El Consejo de Administración podrá exigir el desembolso del 75 por 100 restante del capital suscrito, siempre que este desembolso sea necesario para hacer frente a las obligaciones del Banco respecto de sus prestamistas.

Dicho desembolso será efectuado por cada Estado miembro en proporción a su cuota de capital suscrito, y en las monedas que necesite el Banco para hacer frente a sus obligaciones.

Art. 6. 1. A propuesta del Consejo de Administración, el Consejo de - Gobernadores podrá decidir, por mayoría cualificada, que los Estados miembros otorguen al Banco préstamos especiales generadores de intereses, en los casos y en la medida en que el Banco tenga necesidad de dichos préstamos para la financiación de determinados proyectos, y el Consejo de Administración justifique que el Banco no está en condiciones de obtener, en los mercados de capitales, los recursos necesarios en condiciones convenientes, habida cuenta de la naturaleza y el objeto de los proyectos que deban financiarse.
2. Los préstamos especiales sólo podrán ser exigidos a partir del comienzo del cuarto año siguiente a la entrada en vigor del Tratado. No deberán exceder en total de 400 millones de unidades de cuenta, ni de 100 millones de unidades de cuenta por año.

3. La duración de los préstamos especiales se establecerá en función de la duración de los créditos o garantias que el Banco se proponga conceder mediante estos préstamos; dicha duración no deberá sobrepasar los veinte años. El Consejo de Gobernadores, por mayoria cualificada y a propuesta del Consejo de Administración, podrá decidir el reembolso anticipado de los préstamos especiales.

4. Los préstamos especiales devengarán anualmente un interés del 4 por 100, a menos que el Consejo de Gobernadores, teniendo en cuenta la evolución y el nivel de los tipos de interés en los mercados de capitales, decida fijar un tipo diferente.

5. Los préstamos especiales deberán ser otorgados por los Estados miembros en proporción a su cuota de capital suscrito; deberán ser desembolsados en la moneda nacional dentro de los seis meses siguientes a su solicitud.

6. En caso de liquidación del Banco, los préstamos especiales de los Estados miembros sólo serán reembolsados una vez que se hayan extinguido las restantes deudas del Banco.

Art. 7. 1. En caso de que la paridad de la moneda de un Estado miembro se redujera en relación con la unidad de cuenta definida en el artículo 4, el importe de la cuota de capital desembolsado por este Estado en su moneda nacional sería ajustado en proporción a la modificación que experimentara la paridad, mediante un desembolso complementario realizado por dicho Estado a favor del Banco. Sin embargo, el importe sobre el que se efectúe el ajuste no podrá sobrepasar el importe total de los préstamos concedidos por el Banco en la moneda de que se trate y de los activos del Barico en esta misma moneda. Este desembolso deberá efec- 
tuarse en un plazo de dos meses o, en la medida en que corresponda a préstamos, en las fechas de vencimiento de estos últimos.

2. En caso de que la paridad de la moneda de un Estado miembro aumentara en relación con la unidad de cuenta definida en el artículo 4, el importe de la cuota de capital desembolsado por este Estado en su moneda nacional seria ajustado en proporción a la modificación que experimentara la paridad, mediante un reembolso realizado por el Banco a favor de dicho Estado. Sin embargo, el importe sobre el que se efectúe el ajuste no podrá sobrepasar el importe total de los préstamos concedidos por el Banco en la moneda de que se trate y de los activos del Banco en esta misma moneda. Este reembolso deberá efectuarse en un plazo de dos meses o, en la medida en que corresponda a préstamos, en las fechas de vencimiento de estos ứltimos.

3. La paridad de la moneda de un Estado miembro, con respecto a la unidad de cuenta definida en el artículo 4, será la relación entre el peso de oro fino contenido en dicha unidad de cuenta y el peso de oro fino correspondiente a la paridad de esta moneda declarada al Fondo Monetario Internacional. De no poder ser así, esta paridad resultará del tipo de cambio, con respecto a una moneda definida o convertible en oro, aplicada por el Estado miembro en sus pagos corrientes.

4. El Consejo de Gobernadores podrá decidir la no aplicación de las disposiciones de los apartados 1 y 2 cuando se haya procedido a una modificación uniformemente proporcional de la paridad de todas las monedas de los países miembros del Fondo Monetario Internacional o de los miembros del Banco.

Podrá, además, por unanimidad y a propuesta del Consejo de Administración, modificar el método de conversión

(2) Párrafo añadido por el articulo 2 del Tratado de 10 de julio de 1975 , por el que se modifican determinadas disposiciones del Protocolo sobre los Estatutos del Banco Europeo de Inversiones. en monedas nacionales de las cantidades expresadas en unidad de cuenta y viceversa (2).

Art. 8. El Banco será administrado y dirigido por un Consejo de Gobernadores, un Consejo de Administración y un Comité de Dirección.

Art. 9. 1. El Consejo de Gobernadores estará compuesto por los ministros que designen los Estados miembros.

2. El Consejo de Gobernadores establecerá las directrices generales de la política crediticia del Banco, en particular por lo que respecta a los objetivos que deberán perseguirse a medida que se avance en la consecución del mercado común.

El Consejo de Gobernadores velará por la ejecución de estas directrices.

3. Además, el Consejo de Gobernadores:

a) Decidirá sobre el aumento del capital suscrito, de conformidad con el apartado 3 del artículo 4;

b) Ejercerá las competencias previstas en el artículo 6 en materia de préstamos especiales;

c) Ejercerá las competencias previstas en los artículos 11 y 13 para el nombramiento y cese de los miembros del Consejo de Administración y del Comité de Dirección;

d) Concederá la excepción prevista en el apartado 1 del artículo 18;

e) Aprobará el informe anual elaborado por el Consejo de Administración;

f) Aprobará el balance anual, así como la cuenta de pérdidas y ganancias; g) Ejercerá las competencias y atribuciones previstas en los artículos 4, 7, $14,17,26$ y 27 (3).

h) Aprobará el reglamento interno del Banco.

4. El Consejo de Gobernadores será competente para tomar, por unanimidad, en el marco del Tratado y de los presentes Estatutos, cualquier decisión

(3) Tal y como ha sido modificado por el artículo 3 del Tratado de 10 de julio de 1965, por el que se modifican determinadas disposiciones del Protocolo sobre los Estatutos del Banco Europeo de Inversiones. 
relativa a la suspensión de la actividad del Banco y a su eventual liquidación.

Art. 10. Salvo disposición en contrario de los presentes Estatutos, el Consejo de Gobernadores tomará sus decisiones por mayoria de los miembros que lo componen. Las votaciones del Consejo de Gobernadores se regirán por las disposiciones del artículo 148 del Tratado.

Art. 11. 1. El Consejo de Administración tendrá competencia exclusiva para decidir sobre la concesión de créditos y garantías y la conclusión de empréstitos; fijará los tipos de interés de los préstamos, así como las comisiones de garantía; velará por la sana administración del Banco; garantizará la conformidad de la gestión del Banco con las disposiciones del Tratado y de los Estatutos y con las directrices generales establecidas por el Consejo de Gobernadores.

Al finalizar el ejercicio, el Consejo de Administración estará obligado a presentar un informe al Consejo de Gobernadores y a publicarlo, una vez aprobado.

2. El Consejo de Administración estará compuesto por 12 administradores y 12 suplentes.

Los administradores serán nombrados por un periodo de cinco años por el Consejo de Gobernadores, previa designación respectiva de los Estados miembros y la Comisión, a razón de:

Dos administradores designados de común acuerdo por los países del Benelux;

Tres administradores designados por

la República Federal Alemana

Tres administradores designados por la República Francesa;

Tres administradores designados por la República Italiana;

Un administrador designado por la Comisión.

Su mandato será renovable.

Cada administrador estarä asistido por un suplente, nombrado en las mismas condiciones y con arreglo al mismo procedimiento que los administradores.
Los suplentes podrán participar en las sesiones del Consejo de Administración; no tendrán derecho de voto, a no ser que sustituyan al titular en caso de impedimento de éste.

El presidente 0 , en ausencia de éste, uno de los vicepresidentes del Comité de Dirección presidirá las sesiones del Consejo de Administración, sin tomar parte en la votación.

Los miembros del Consejo de Administración se elegirán entre personalidades que ofrezcan garantias plenas de independencia y competencia; sólo serán responsables ante el Banco.

3. Sólo cuando un administrador deje de reunir las condiciones necesarias para el ejercicio de sus funciones, podrá ser cesado por el Consejo de Gobernadores, por mayoría cualificada.

La no aprobación del informe anual llevará consigo la dimisión del Consejo de Administración.

4. En caso de vacante por fallecimiento, cese, dimisión voluntaria o colectiva se procederá a su sustitución, de conformidad con lo dispuesto en el apartado 2. Salvo en caso de renovación total, los miembros serán sustituidos por el tiempo que falte para terminar el mandato.

5. El Consejo de Gobernadores fijará la retribución de los miembros del Consejo de Administración. Determinará, por unanimidad, las eventuales incompatibilidades con las funciones de administrador y de suplente.

Art. 12. 1. Cada administrador dispondrá dé un voto en el Consejo de Administración.

2. Salvo disposición en contrario de los presentes Estatutos, - el Consejo de Administración tomará sus decisiones por mayoria simple de sus miembros con derecho de voto. La mayoria cualificada requerirá un total de ocho votos. El Reglamento interno del Banco fijará el quórum necesario para la validez de los acuerdos del Consejo de Administración.

Art. 13. 1. El Comité de Dirección estará compuesto por un presidente y 
dos vicepresidentes nombrados para un periodo de seis años por el Consejo de Gobernadores, a propuesta del Consejo de Administración. Su mandato será renovable.

2. A p̀ropuesta del Consejo de Administración, por 'mayoria cualificada, el Consejo de Gobernadores; también por mayoria cualificada, podrá cesar a los miembros del Comité de Dirección.

3. El Comité de Dirección se encargará de la gestión de los asuntos de administración ordinaria del Banco, bajo la autoridad del presidente y el control del Consejo de Administración.

Dicho Comité preparará las decisiones del Consejo de Administración, especialmente las referentes a la conclusión de empréstitos y a la concesión de créditos y garantías; asimismo, asegurará la ejecución de dichas decisiones.

4. El Comité de Dirección emitirá, por mayoria, sus dictámenes sobre los proyectos de préstamos y garantias, asi como sobre los proyectos de empréstitos.

5. El Consejo de Gobernadores fijará la retribución de los miembros del Comitê de Dirección y determinará las incompatibilidades con sus funciones.

6. El presidente o, en caso de impedimento de éste, uno de los vicepresidentes representará al Banco en los asuntos judiciales o extrajudiciales.

7. Los funcionarios y empleados del Banco estarán sometidos a la autoridad del presidente. Corresponderá a éste su contratación y despido. En la elección del personal, se deberá tener en cuenta no sólo las aptitudes personales y la formación profesional, sino también un reparto equitativo entre los nacionales de los Estados miembros.

8. El Comité de Dirección y el personal del Banco sólo serán responsables ante este último y ejercerán sus funciones con total independencia.

Art. 14. 1. Un Comité, compuesto por tres miembros nombrados por el Consejo de Gobernadores, en razón de su competencia, comprobará cada año la regularidad de las operaciones y de los libros del Banco.

2. Dicho Comité confirmará que el balance y la cuenta de pérdidas y ganancias concuerdan con los asientos contables y que reflejan exactamente la situación del Banco, tanto respecto del activo como del pasivo.

Art. 15. El Banco se relacionará con cada Estado miembro por medio de la autoridad que éste designe. En la ejecuciónde las operaciones financieras podrá recurrir al Banco de emisión del Estado miembro interesado o a otras instituciones financieras autorizadas por éste.

Art. 16. 1. El Banco cooperará con todas aquellas organizaciones internacionales que ejerzan su actividad en campos análogos a los suyos.

2. El Banco tratará de establecer todo tipo de contactos útiles con objeto de cooperar con las instituciones bancarias y financieras de los países por donde se extiendan sus operaciones.

Art. 17. A instancia de un Estado miembro o de la Comisión, o por propia iniciativa, el Consejo de Gobernadores interpretará o completará, en las mismas condiciones con que fueron fijadas, las directrices que hubiere establecido de conformidad con el artículo 9 de los presentes Estatutos.

Art. 18. 1. En el ámbito del mandato definido en el artículo 130 del Tratado, el Banco otorgará créditos a sus miembros o a las empresas privadas o públicas para aquellos proyectos de inversión que deban ejecutarse en los territorios europeos de los Estados -miembros, siempre que no se disponga, en condiciones razonables, de recursos procedentes de otras fuentes.

Sin embargo, en virtud de una excepción concedida por unanimidad por el Consejo de Gobernadores, a propuesta del Consejo de Administración, el Banco podrá otorgar créditos para aquellos proyectos de inversión que deban ejecutarse, total o parcialmente, fuera de los territorios europeos de los Estados miembros. 
2. La concesión de préstamos estará subordinada, en la medida de lo posible, a la utilización de otros medios de financiación.

3. Cuando se conceda un préstamo a una empresa o a una colectividad que no sea un Estado miembro, el Banco subordinará la concesión de dicho préstamo al otorgamiento de una garantia por el Estado miembro en cuyo territorio haya de ejecutarse el proyecto o de otras garantias suficientes.

4. El Banco podrá garantizar los empréstitos contratados por empresas públicas o privadas o por colectividades para la realización de las operaciones previstas en el artículo 130 del Tratado.

5. El importe total comprometido de los préstamos y garantías concedidos por el Banco no deberá exceder del 250 por 100 del capital suscrito.

6. El Banco se protegerá contra el riesgo de cambio insertando en los contratos de préstamo y de garantía las cláusulas que considere apropiadas.

Art. 19. 1. Los tipos de interés de los préstamos que conceda el Banco, asî como las comisiones de garantia, habrán de adaptarse a las condiciones que prevalezcan en el mercado de capitales y deberán calcularse de manera que los ingresos que resulten de los mismos permitan al Banco hacer frente a sus obligaciones, cubrir sus gastos y constituir un fondo de reserva de conformidad con el artículo 24.

2. El Banco no concederá ninguna reducción de los tipos de interés. En caso de que, habida cuenta del carácter específico del proyecto que deba financiarse, resulte conveniente una reducción del tipo de interés, el Estado miembro interesado u otra autoridad podrá conceder bonificaciones de intereses, en la medida en que su concesión sea compatible con las normas previstas en el artículo 92 del Tratado.

Art. 20. En sus operaciones de préstamo y garantía, el Banco deberá observar los principios siguientes:
1. Velará porque sus fondos sean utilizados de la forma más racional posible, en interés de la Comunidad.

Sólo podrá conceder préstamos o garantizar empréstitos:

a) Cuando pueda asegurarse el pago de los intereses y la amortización del capital con los beneficios de explotación, tratándose de proyectos ejecutados por empresas pertenecientes al sector de la producción, o por medio de un compromiso suscrito por el Estado donde se ejecute el proyecto, o de cualquier otro modo, en el caso de otros proyectos;

b) y cuando la ejecución del proyecto contribuya al incremento de la productividad económica en general y favorezca la consecución del mercado común.

2. No deberá adquirir ninguna participación en empresas ni asumir ninguna responsabilidad en la gestión de éstas, a menos que la protección de sus derechos asi lo exija para garantizar la recuperación de sus créditos.

3. Podrá ceder sus créditos en el mercado de capitales y, a tal fín, podrá exigir de sus prestatarios la emisión de obligaciones o de otros titulos.

4. Ni él ni los Estados miembros deberán imponer condiciones que obliguen a gastar las cantidades prestadas dentro de un Estado miembro determinado.

5. Podrá subordinar la concesión de préstamos a la organización de licitaciones internacionales.

6. No financiará, total o parcialmente, los proyectos a los que se oponga el. Estado miembro en cuyo territorio deban ejecutarse.

Art. 21. 1. Las solicitudes de préstamo o de garantía podrán ser cursadas al Banco por conducto de la Comisión o del Estado miembro en cuyo territorio deba realizarse el proyecto. Asimismo, cualquier empresa podrá presentar directamente al Banco una solicitud de préstamo o de garantia.

2. Cuando las solicitudes sean cursadas por conducto de la Comisión, se someterán al dictamen del Estado 
miembro en cuyo territorio vaya a realizarse el proyecto. Cuando sean cursadas por medio del Estado miembro, se someterán al dictamen de la Comisión. Cuando provengan directamente de una empresa, se someterán al Estado miembro interesado y a la Comisión.

Los Estados miembros interesados y la Comisión deberán emitir su dictamen en el plazo máximo de dos meses. A falta de respuesta en el plazo indicado, el Banco podrá considerar que el mencionado proyecto no suscita objeción alguna.

3. El Consejo de Administración decidirá sobre las solicitudes de préstamo o de garantía que le someta el Comité de Dirección.

4. El Comité de Dirección examinará si las solicitudes de préstamo o de garantía presentadas se atienen a las disposiciones de los presentes Estatutos, en particular a las del artículo 20 . Si el Comité de Dirección se pronuncia en favor de la concesión de un préstamo o de una garantía, deberá -someter el proyecto de contrato al Consejo de Administración; podrá subordinar su dictamen favorable a las condiciones que considere esenciales. Si el Comité de Dirección se pronuncia en contra de la concesión del préstamo o de la garantia, deberá presentar al Consejo de Administración los documentos pertinentes, acompañados de su dictamen.

5. En caso de dictamen desfavorable del Comité de Dirección, el Consejo de - Administración sólo podrá conceder el préstamo o la garantía mencionados por unanimidad.

6. En caso de dictamen desfavorable de la Comisión, el Consejo de Administración sólo podrá conceder el préstamo o la garantía mencionados por unanimidad, absteniéndose de votar el administrador nombrado previa designación de la Comisión.

7. En caso de dictamen desfavorables del Comité de Dirección y de la Comisión, el Consejo de Administración no podrá conceder el préstamo o la garantia mencionados.
Art. 22. 1. El Banco tomará a préstamo en los mercados internacionales de capitales los recursos' necesarios para el cumplimiento de su misión.

2. El Banco podrá tomar dinero a préstamo en el mercado de capitales de un Estado miembro, en el marco de las disposiciones legales aplicables a las emisiones internas 0 , a falta de tales disposiciones en un Estado miembro, cuando dicho Estado miembro y el Banco se hayan concertado y puesto de acuerdo sobre el empréstito previsto por éste.

El consentimiento de las autoridades competentes del Estado miembro sólo podrá ser denegado si hay motivos para tener graves perturbaciones en el mercado de capitales de dicho Estado.

Art. 23. 1. El Banco podrá utilizar, en las condiciones siguientes, los recursos disponibles que no necesite inmediatamente para hacer frente a sus obligaciones:

a) Podrá colocar capitales en los mercados monetarios;

b) salvo lo dispuesto en el apartado 2 del artículo 20, podrá comprar o vender títulos emitidos por él mismo o por sus prestatarios;

c) podrá efectuar cualquier otra operación financiera relacionada con sus objetivos.

2. Sin perjuicio de lo dispuesto en el artículo 25, el Banco no efectuará, en la gestión de sus colocaciones de capital, ningün arbitraje de divisas que no sea estrictamente indispensable para poder realizar sus préstamos o para el cumplimiento de los compromisos contraidos en razón de los empréstitos emitidos o de las garantias otorgadas por él.

3. En el ámbito de aplicación del presente artículo, el Banco actuará de acuerdo con las autoridades competentes de los Estados miembros o sus Bancos de emisión.

Art. 24. 1. Se constituirá progresivamente un fondo de reserva equivalente al 10 por 100 como máximo del capital suscrito. Si la situación de los 
compromisos del Banco lo justificare, el Consejo de Administración podrá decidir la constitución de reservas suplementarias. Mientras este fondo de reserva no esté enteramente constituido, podrá ser alimentado con:

a) Los intereses que produzcan los prestamos concedidos por el Banco con las cantidades que deban aportar los Estados miembros en virtud del artículo 5 :

b) los intereses que produzcan los préstámos concedidos por el Banco con las cantidades procedentes del reembolso de los préstamos mencionados en la letra a), siempre que estos ingresos no sean necesarios para hacer frente a las obligaciones y sufragar los gastos del Banco.

2. Los recursos del fondo de reserva deberán colocarse de forma que estén en condiciones de responder, en cualquier momento, a los fines del fondo.

Art. 25. 1. El Banco estará siempre autorizado para transferir a una de las monedas de los Estados miembros los activos que posea en la moneda de otro Estado miembro para realizar las operaciones financieras que sean conformes a su objeto definido en el artículo $130 \mathrm{del}$ Tratado, teniendo en cuenta lo dispuesto en el artículo 23 de los presentes Estatutos. El Banco evitará, en la medida de lo posible, proceder a tales transferencias si posee activos disponibles o realizables en la moneda que precise.

2. El Banco no podrá convertir en divisas de terceros países los activos que posea en la moneda de uno de los Estados miembros sin el consentimiento de dicho Estado.

3. El Banco podrá disponer libremente de la parte de su capital desembolsado en oro o en divisas convertibles, así como de las divisas tomadas a préstamo en los mercados de terceros paises.

4. Los Estados miembros se comprometen a poner a disposición de los deudores del Banco las divisas nece- sarias para el reembolso del capital y el pago de los intereses de los préstamos concedidos o garantizados por el Banco para los proyectos que deban ejecutarse en su territorio.

Art. 26. Si un Estado miembro incumpliere las obligaciones que como miembro le incumben en virtud de los presentes Estatutos, en especial la obligación de desembolsar su cuota, de hacer efectivos sus préstamos especiales o de asegurar el servicio de sus empréstitos, el Consejo de Gobernadores podrá, mediante decisión tomada por mayoría cualificada, suspender la concesión de préstamos o garantías a dicho Estado miembro o a sus nacionales.

Esta decisión no eximirá al Estado ni a sus nacionales del cumplimiento de sus obligaciones para con el Banco.

Art. 27. 1. Si el Consejo de Gobernadores decidiere suspender la actividad del Banco, deberán interrumpirse sin demora todas las actividades, con excepción de las operaciones necesarias para asegurar la debida utilización, protección y conservación de sus bienes, así como para saldar sus compromisos.

2. En caso de liquidación, el Consejo de Gobernadores nombrará a los liquidadores y les dará instrucciones para efectuar dicha liquidación.

Art. 28. 1. El Banco gozará en cada uno de los Estados miembros de la más amplia capacidad jurídica que las legislaciones nacionales reconocen a las personas juridicas; podrá, en particular, adquirir y enajenar bienes muebles o inmuebles y comparecer en juicio.

Los privilegios è inmunidades del Banco se definirán en el protocolo previsto en el artículo 218 del Tratado.

2. Los bienes del Banco estarán exentos de toda requisa o expropiación, cualquiera que sea su forma.

Art. 29. Los litigios entre el Banco, por una parte, y sus prestamistas, sus prestatarios o terceros, por otra, serán 
resueltos por los órganos jurisdiccionales nacionales competentes, sin perjuicio de las competencias atribuidas al Tribunal de Justicia.

El Banco deberá fijar domicilio en cada uno de los Estados miembros. Sin embargo, podrá designar, en un contrato, un domicilio especial o prever un procedimiento de arbitraje.

Los bienes y activos del Banco sólo podrán ser embargados o sometidos a ejecución forzosa por decisión judiçial.

Hecho en Roma, el 25 de marzo de 1957.

P. H. SpaAk, J. Ch. SNoy et ADENAUER, D'OPPUERS, Pineau, Hallstein, ANTONIO SEgNi, M. FAURE, BECH, J. LuNs, Gaetano Martino, LAMBERT SCHAUS, J. LINTHORST HOMAN 
DA-1985-1986, núms. 206-207: Protocolo sobre los Estatutos del Banco Europeo de Inversione...

DA-1985-1986, núms. 206-207. Protocolo sobre los Estatutos del Banco Europeo de Inversione... 


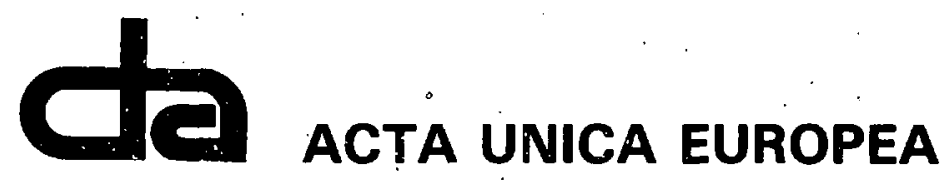

DA-1985-1986, núms. 206-207. Protocolo sobre los Estatutos del Banco Europeo de Inversione... 
DA-1985-1986, númș. 206-207. Protocolo sobre los Estatutos del Banco Europeo de Inversione...

DA-1985-1986, núms. 206-207. Protocolo sobre los Estatutos del Banco Europeo de Inversione... 